\title{
Antecedent Precipitation Tool (APT) Version 1.0: Technical and User Guide
}

by Joseph L. Gutenson and Jason C. Deters

PURPOSE: This document provides an overview of the technical components of the Antecedent Precipitation Tool (APT) and a user guide for using the APT. The APT is an automation tool that the US Army Corps of Engineers (USACE) developed to facilitate the comparison of antecedent or recent precipitation conditions for a given location to the range of normal precipitation conditions that occurred during the preceding $30 \mathrm{yr}^{1}$. In addition to providing a standardized methodology to evaluate normal precipitation conditions ("precipitation normalcy"), the APT can assess the presence of drought conditions and the approximate dates of the wet and dry seasons for a given location.

BACKGROUND: The APT automates an existing methodology in which a method of evaluating 30-day rolling totals of precipitation is combined with the Natural Resources Conservation Service (NRCS) Engineering Field Handbook weighting factors ("combined method") (NRCS 1997), which provides utility in evaluating normal precipitation conditions (precipitation normalcy) for individual dates at an individual site (Sprecher and Warne 2000). In addition to providing a standardized methodology to evaluate precipitation normalcy, the APT also provides two additional indices of longer-term hydrologic input:

1. The presence of drought conditions using the Palmer Drought Severity Index (PDSI) (Palmer 1965).

2. The approximate dates of the wet and dry seasons for a given location using the Web-based, Water-Budget, Interactive, Modeling Program (WebWIMP) (University of Delaware 2009).

USACE originally developed the APT to streamline and automate the evaluation of precipitation normalcy and other climatic variables to complete wetland delineations whenever an assessment of the following site-specific conditions is necessary: dry season, drought conditions, lower than normal antecedent precipitation, or greater than normal antecedent precipitation (USACE 2008). The methodology underlying the APT precipitation normalcy calculation has demonstrated success in determining precipitation normalcy for hydric soil and wetland determinations (Vepraskas et al. 2019). In addition to informing wetland delineations, the APT can assist in determining whether observations are representative of normal climatic conditions when evaluating whether certain aquatic resources are jurisdictional under the Clean Water Act as "waters of the United States."

Under the now-vacated Navigable Waters Protection Rule (NWPR), determining the jurisdictional status of certain waterbodies was informed by an understanding of the hydrologic flows and surface water connections that occur under "typical year" conditions (i.e., meaning when precipitation and other climatic variables are within the normal periodic range for the geographic

\footnotetext{
${ }^{1}$ For a full list of the spelled-out forms of the units of measure used in this document, please refer to US Government Publishing Office Style Manual, 31st ed. (Washington, DC: US Government Publishing Office 2016), 248-52, https://www.govinfo.gov/content/pkg/GPO-STYLEMANUAL-2016/pdf/GPO-STYLEMANUAL-2016.pdf.
} 
area of the applicable aquatic resource based on a rolling $30 \mathrm{yr}$ period). For the purposes of the NWPR, an evaluation of typical year conditions was required when determining whether certain aquatic resources are jurisdictional. Some locations in the country have ample data to determine streamflow conditions or surface water connections in a typical year. However, in the absence of, or with limited availability of, site-specific hydrologic data, US Environmental Protection Agency (EPA) and USACE (the agencies) intended to use the APT as a resource for evaluating whether observations or measurements of streamflow conditions and surface water connections are representative of typical year conditions when assessing the jurisdictional status of certain aquatic features. An APT analysis can be conducted to determine the normal periodic range of precipitation for any point-in-time resources, which are sources of information that reflect flow or surface water conditions at a specific location on a specific date (e.g., aerial photographs or data collected during a site visit).

\section{APT TECHNICAL DETAILS}

The APT calculates an Antecedent Precipitation Score for a given observation point and observation date using historic precipitation data. The Antecedent Precipitation Score serves as a measurement of precipitation normalcy that translates into a description of precipitation normalcy by the Antecedent Precipitation Condition (e.g., normal, wet, or dry conditions) for the observation point and observation date. All precipitation data the APT uses to calculate the Antecedent Precipitation Score come from the National Oceanic and Atmospheric Administration (NOAA) Global Historic Climatology Network (GHCN)-Daily precipitation dataset (Menne et al. 2012; NOAA 2021a). An observation point designates the user-defined location of interest for running the APT. The user of the APT identifies an observation point using a single latitude and longitude. The user also identifies an observation date using a month, day, and year. The APT calculates an Antecedent Precipitation Score by one of two general means, as specified by the user: single-point or watershed analysis. In the APT single-point or watershed analysis, the APT may select weather data from a GHCN station outside of the observation point's drainage area. Selecting a GHCN station outside of the observation point's watershed will be an important consideration when interpreting the results of the antecedent period in regions where extreme precipitation events can be highly localized (e.g., recent storm events that have occurred in one adjacent watershed but not another).

\section{Single-Point Analysis}

Antecedent precipitation score. When the user runs a single-point analysis, the APT builds one, $30 \mathrm{yr}$ precipitation climatology and compares the antecedent 90-day period to this precipitation climatology for the observation point using the combined method described above, as recommended by Sprecher and Warne (2000). The first step in this single-point analysis is for the APT to identify the primary station or the weather station within the GHCN where the APT primarily derives the precipitation climatology. The primary station selection process must overcome a lack of GHCN stations with complete historical records. Thus, the primary station selection process includes a dual-layered determination: (1) a weighted distance ranking and (2) assessment of record completeness. Weighted distance ranking occurs by assessing the linear distance and elevation differences from the observation point to GHCN stations using the formula:

$$
\delta_{i}=\varphi_{i}\left(\frac{\rho_{i}}{1,000}+0.45\right)
$$


In Equation 1, $\delta_{i}$ is the weighted distance from the GHCN station $i$ to the observation point in units of miles*feet, $\varphi_{i}$ is the linear distance from the $i$ th GHCN station to the observation point in units of miles, and $\rho_{i}$ is the difference in elevation between the $i$ th GHCN station and the observation point in units of feet. By working with experienced USACE Project Managers from across the United States and ascertaining their best professional judgement, the developers arrived at the formulation of Equation 1. The APT assesses the weighted distance for all stations within a $\varphi_{i}=$ $48 \mathrm{~km}(30 \mathrm{mi})$ radius using this weighted distance formula. If additional station data are necessary due to data gaps at stations within the $48 \mathrm{~km}$ (30 mi) radius, the APT will sequentially increase the radius until either completing a $30 \mathrm{yr}$ time series, reaching the maximum search radius, or using the maximum number of stations (15 GHCN stations). If the latitude of the observation point is less than $50^{\circ}$ latitude (i.e., in the contiguous United States), the radius of the search distance will incrementally increase by $16 \mathrm{~km}(10 \mathrm{mi})$ and extend to a maximum of $97 \mathrm{~km}(60 \mathrm{mi})$. If the latitude of the observation point is greater than or equal to $50^{\circ}$ latitude (e.g., in Alaska), the search distance will incrementally increase by $48 \mathrm{~km}(30 \mathrm{mi})$ and extend to a maximum of $805 \mathrm{~km}(500 \mathrm{mi})$. A ranked list of GHCN stations is determined by ordering GHCN stations based upon $\delta_{i}$ values. The APT acquires approximate elevation values for the observation point and each GHCN station from the US Geological Survey (USGS) Elevation Point Query Service (EPQS). The EPQS determines elevation values from the 1/3 arc second ( 10 m) National Elevation Dataset (USGS 2017; Gesch et al. 2002, 2010).

In determining the APT primary station, the APT also assesses the completeness of the precipitation records for each GHCN station in the ranked list of GHCN stations. The first iteration of the APT used only GHCN stations that possessed complete historic records. This process led to APT primary station determinations that did not approximate USACE Project Managers best professional judgement. Many GHCN stations lack complete precipitation records for the necessary time span, leading to primary station selections that were distant from observation points. To improve this process within the APT, the required number of records necessary to determine the primary station were decreased. A nationwide assessment of the APT found that at least 68 daily records for the APT within the 90 -day antecedent period ( $>75 \%$ ) and greater than 6,000 daily records in the $30 \mathrm{yr}$ normal period is optimal in deciding the primary station. The APT gives ranking preference to any GHCN stations with at least 8,000 daily records within the normal period and gives further ranking preference to stations with greater than 10,000 daily records within the normal period. The APT iterates through the ranked list of GHCN stations. If a GHCN station meets the minimum record length specifications, the APT assesses the number of records and the $\delta_{i}$ value for the station. The GHCN station that has the lowest weighted difference $\left(\delta_{\min }\right)$ for the GHCN stations in the ranked list and meets the minimum records specifications will be the chosen primary station, unless a GHCN station with $\delta_{i}>\delta_{\min }$ has greater than 8,000 daily records and meets the following criteria:

$$
\delta_{8000}<2 \tau \delta_{\min }
$$

In Equation 2, $\delta_{8000}$ is the lowest weighted difference of the GHCN station with greater than 8,000 daily records within the normal period, and $\tau$ is a distance toleration factor, that is currently set to 0.75 based upon evaluation by the development team.

Similarly, if a GHCN station in the ranked list of GHCN stations has $\delta_{i}>\delta_{\min }$ and greater than 10,000 records in the normal period, this GHCN station becomes the primary station if meeting the following criteria: 


$$
\delta_{10000}<4 \tau \delta_{\min }
$$

In Equation 3, $\delta_{10000}$ is the lowest weighed difference of the GHCN station with greater than 10,000 daily records in the normal period.

If GHCN stations meet the $\delta_{8000}$ and $\delta_{10000}$ criteria specified above, the APT selects the $\delta_{10000}$ if the following criteria are met in Equation 4:

$$
\delta_{10000}<2 \tau \delta_{8000}
$$

Otherwise, the GHCN station meeting the $\delta_{8000}$ criterion is the primary station.

Once the APT selects a primary station from the ranked list, the APT determines where values are missing in the primary station records and which GHCN stations fill those values. The APT determines which GHCN station fills the data gaps in the primary station records by calculating $\delta_{i}$ between the primary station and other GHCN stations. The APT reorders GHCN stations based upon the recalculated $\delta_{i}$ values and those stations are sequentially used to backfill data gaps in the primary station records. There are no minimum record completeness requirements for selecting GHCN stations that fill primary station data gaps. As data filling occurs within each search radius, if greater than 5 days of data gap remain in the record, the primary station selection process and subsequent data filling will repeat at the increased search radius. If gaps in the primary station records persist after $15 \mathrm{GHCN}$ stations are used or the APT reaches the maximum search radius to backfill the primary station records, the APT performs a linear interpolation between the first observation before the data gap and when observations in the primary station record return. The number of continuous days within a data gap cannot be greater than one day in order for linear interpolation to fill the gap.

After the APT completes a full data record for a primary station, the APT calculates 30-day rolling precipitation totals and a $30 \mathrm{yr}$ climatology for these 30-day rolling totals for each day of the year. The APT compares rolling 30-day totals for three annotation points to the $30 \mathrm{yr}$ climatology: the observation date (including precipitation on the observation date), the date that falls 30 days prior to the observation date, and the date that falls 60 days prior to the observation date. ${ }^{1}$ This methodology derives from Sprecher and Warne (2000) and NRCS (1997) and is summarized as the following expression:

$$
\alpha=\sum_{j=1}^{n} \gamma_{j} \omega_{j}
$$

In Equation 5, $\alpha$ is the Antecedent Precipitation Score, $\gamma_{j}$ is the condition value assigned for the $j$ th 30 -day annotation point, $\omega_{j}$ is the weighing value assigned to the $j$ th 30 -day annotation point, and $n$ is the number of annotation points or rolling periods. If the 30 -day rolling total for the $j$ th annotation point falls below the 30th percentile in the $30 \mathrm{yr}$ climatology, $\gamma_{j}=1$. If the 30-day rolling total for the $j$ th annotation point falls between the 30th and 70th percentile in the $30 \mathrm{yr}$ climatology, $\gamma_{j}=2$. If the 30 -day rolling total for the $j$ th annotation point falls above the 70 th

\footnotetext{
${ }^{1}$ If the water year of the observation date falls on a leap year, the APT does not calculate February 29th percentiles. Instead, the APT averages the February 28 and March 1 percentiles.
} 
percentile in the $30 \mathrm{yr}$ climatology, $\gamma_{j}=3$. There are currently three annotation points for three rolling periods $(n=3)$. If the $j$ th 30 -day annotation point is the observation date, $\omega_{j}=3$ for $j$ th 30 day annotation point. If the $j$ th 30 -day annotation point is the 30 days before the observation date, $\omega_{j}=2$ for $j$ th 30 -day annotation point. If the $j$ th 30 -day annotation point is 60 days before the observation date, $\omega_{j}=1$ for $j$ th 30 -day annotation point. The APT assigns categorical summaries, termed the Antecedent Precipitation Conditions for each Antecedent Precipitation Score. Table 1 summarizes the Antecedent Precipitation Score categories.

\begin{tabular}{|c|c||}
\hline \multicolumn{2}{|c|}{ Table 1. Antecedent Precipitation Score categories derived from NRCS (1997). } \\
\hline $\begin{array}{c}\text { Antecedent Precipitation Score }(\boldsymbol{\alpha}) \text { Range } \\
\text { Where } \boldsymbol{n}=\mathbf{3}\end{array}$ & Antecedent Precipitation Condition \\
\hline Antecedent Precipitation Score $<10$ & Drier than Normal \\
\hline $10 \leq$ Antecedent Precipitation Score $<15$ & Normal Conditions \\
\hline $15 \leq$ Antecedent Precipitation Score & Wetter than Normal \\
\hline
\end{tabular}

WebWIMP and PDSI. The APT calculates the Antecedent Precipitation Score independent of the WebWIMP and PDSI calculations. However, for each observation point, the APT provides the user with wet season/dry season and drought conditions using the WebWIMP and PDSI, respectively.

USACE (2008) advises the use of the WebWIMP in approximating wet or dry season context for the purposes of wetland delineation. WebWIMP is a web application developed and maintained by the University of Delaware (University of Delaware 2009). WebWIMP provides an interface to global monthly water balance estimates that are a gridded raster product with a $0.5^{\circ}$ horizontal resolution. The methodology powering WebWIMP calculates the monthly water balance estimates based upon a global network of over 13,000 weather observation stations (Wilmott et al. 1981a,b). A modified form of the Thornthwaite scheme (Thornthwaite 1948) calculates estimates of monthly average potential evapotranspiration (PET) (AMS 2012) using average monthly surface air temperature. WebWIMP presents these resulting differences for the weather observation stations as an interpolated, spatially continuous raster (Willmott et al. 1985). The difference between average monthly precipitation and an estimate of monthly average PET indicates when the wet or dry season occurs. A negative difference between monthly precipitation and PET indicates the dry season. A positive difference indicates the wet season (USACE 2008).

One limitation of WebWIMP data is that the Thornthwaite methodology estimates PET. PenmanMontheith or other radiation-based means of estimating PET are generally preferred over temperature-based approaches, such as Thornthwaite. However, temperature-based approaches rely upon readily available meteorological inputs like temperature while radiation-based approaches require meteorological data that are available less frequently (van der Schrier et al. 2011; Lang et al. 2017). Further, the spatial and temporal resolution of WebWIMP is relatively coarse and may limit the WebWIMP effectiveness during transitional periods between the wet season and dry season. The APT uses the observation point's geographic location to determine which WebWIMP grid cell into which the observation point falls. The APT then assigns wet or dry season to the APT analysis using the WebWIMP difference between monthly precipitation and PET for the month of the observation date within that grid cell. Table 2 lists the categorical summaries of WebWIMP wet season and dry season categorical assignment (USACE 2008). 


\begin{tabular}{|c|c||}
\hline \hline \multicolumn{2}{|c||}{ Table 2. WebWIMP values and associated seasonal categories derived from USACE (2008). } \\
\hline \hline Difference between monthly average precipitation and PET & Range Descriptor \\
\hline$\geq 0$ & Wet Season \\
\hline$<0$ & Dry Season \\
\hline
\end{tabular}

The APT queries the NOAA monthly PDSI calculations within the NOAA Climate Divisional Database (nClimDiv) to determine whether drought conditions are present for a given observation point (NOAA 2014; Vose et al. 2014). The PDSI is a cumulative index estimated by calculating a water balance using observed precipitation and calculated PET (Palmer et al. 1965). Like the WebWIMP, the PDSI uses the Thornthwaite approach to calculate PET while Penman-Montheith or other radiation-based approaches to PET calculation are generally preferred (Lang et al. 2017). The PDSI also treats all precipitation, including snowfall, as liquid precipitation and does not account for vegetative or soil conditions in evaporation calculations. Further, because of the monthly time-step, the PDSI does not reflect short-term hydrologic conditions. However, previous research has shown that the PDSI value correlates well with observed soil moisture and streamflow, particularly during warm seasons in the United States (Dai et al. 2004; Dai 2011, 2012). NOAA provides PDSI calculations for 350 climate divisions across the United States and Puerto Rico (NOAA 2005). The APT uses the latitude and longitude of the observation point to determine into which climate division the observation point falls. The APT assigns that climate region's PDSI value during the period of interest to the observation point. Categorical summaries are determined for each PDSI range. Table 3 summarizes the PDSI categories detailed by Palmer (1965).

\begin{tabular}{|c|c||}
\hline \hline \multicolumn{2}{||c||}{ Table 3. PDSI values and associated categories (from Palmer [1965]). } \\
\hline \hline PDSI Range & Range Descriptor \\
\hline PDSI $=-99.99$ & Not available \\
\hline $4<\mathrm{PDSI}$ & Extreme wetness \\
\hline $3<\mathrm{PDSI} \leq 4$ & Severe wetness \\
\hline $2<\mathrm{PDSI} \leq 3$ & Moderate wetness \\
\hline $1<\mathrm{PDSI} \leq 2$ & Mild wetness \\
\hline $0.5<\mathrm{PDSI} \leq 1$ & Incipient wetness \\
\hline$-0.5<\mathrm{PDSI} \leq 0.5$ & Normal \\
\hline$-1<\mathrm{PDSI} \leq-0.5$ & Incipient drought \\
\hline$-2<\mathrm{PDSI} \leq-1$ & Mild drought \\
\hline$-3 .<\mathrm{PDSI} \leq-2$ & Moderate drought \\
\hline$-4<\mathrm{PDSI} \leq-3$ & Severe drought \\
\hline $\mathrm{PDSI} \leq-4$ & Extreme drought \\
\hline
\end{tabular}

\section{Watershed Analysis}

An APT watershed analysis undergoes the same processes as those described above for the singlepoint analysis. However, the assessment process occurs at randomly assigned sampling points within a specified watershed assigned to the observation point. An observation point's watershed area can be designated using the USGS National Water Boundary Database (WBD) hydrologic unit code (HUC) 8, 10, and 12 boundaries or through a custom watershed polygon. WBD HUCs 
are nested hydrographic features that hierarchically organize, classify, and map surface water features in the United States. The hierarchy assigns two digits at each level of the hierarchy, as the geographic range of an area narrows from a regional 2-digit level (HUC 2) to an 8-digit subbasins (HUC 8), 10-digit watersheds (HUC 10), 12-digit subwatersheds (HUC 12), and so forth (Seaber et al. 1987; USGS and NRCS; 2013). Using a HUC 8, 10, or 12 in the APT watershed analysis will not account for any upstream HUCs and will utilize the entire HUC area in which the observation point falls. A custom watershed analysis can overcome the limitations associated with the use of a HUC 8, 10, or 12. The user must generate the custom watershed using a third-party tool such as the EPA Watershed Assessment, Tracking \& Environmental Results System (WATERS) Web Services (EPA 2021) or the ArcGIS Pro Watershed tool (ESRI 2022). The user may select which type of watershed analysis to run.

The APT randomly assigns sampling points within the designated watershed area. The APT randomly generates points within the minimum and maximum latitude and longitude values for the watershed and tests them against two sampling conditions. First, the APT will test whether the point falls within the watershed. Second, the APT will test whether the point is closer to any of the previously selected sampling points than the default sampling point spacing distance. To ensure optimum point dispersion on all watersheds, the point spacing was lowered during the development of the APT watershed analysis until reaching an optimum value of $6 \mathrm{~km}(3.75 \mathrm{mi})$. In the case of each HUC, the sampling process repeats until 1,500 consecutive sampling points fail one of the two tests above or, in the case of the custom watershed, when 3,000 consecutive sampling points fail one of the two sampling tests above.

Once the APT develops a list of sampling points, the APT calculates the Antecedent Precipitation Score for each sampling point, determines the seasonality using WebWIMP, and assesses drought conditions using the NOAA nClimDiv monthly PDSI for each sampling point. The APT then averages all the sampling point Antecedent Precipitation Scores to represent Antecedent Precipitation Score for the observation point.

\section{APT USER GUIDE}

\section{Installation Instructions}

The user must undertake several steps to install the APT on the desktop:

1. The user can access the APT by navigating to the APT Github release page at https://github.com/erdc/Antecedent-Precipitation-Tool/releases and opening the "Antecedent Precipitation Tool.exe" file, located in the "Antecedent.Precipitation.Calculator. $7 z$ " folder. Please note that this version of the APT functions only on Windows machines.

2. The user must extract the operational code by using the 7-zip File Manager software, available for download at https://www.7-zip.org/. Extracting the code to the user's desktop is suggested.

3. Once extracted, the user will then have access to the "Antecedent Precipitation Calculator" directory. To access the tool's functionality, the user should navigate the 
"Antecedent Precipitation Tool" directory to find the "" file. The "Antecedent Precipitation Tool" directory contains all of the files necessary to operate the APT.

4. Double-clicking the "main_ex.exe" file will open the APT Microsoft DOS (MS-DOS) window. This window will provide the user with feedback when the tool is operating that will be useful in diagnosing particular issues that the user might encounter.

5. If the user is operating the APT for the first time, the APT will create a copy of the "Antecedent Precipitation Tool.exe" file on the user's desktop and name this file "Antecedent Precipitation Tool.exe" for easy access.

6. To ensure the inputs utilized by the APT are up to date, the system will automatically check for and install updates

7. The APT MS-DOS window will launch the APT graphical user interface (GUI). Figure 1 illustrates the current GUI.

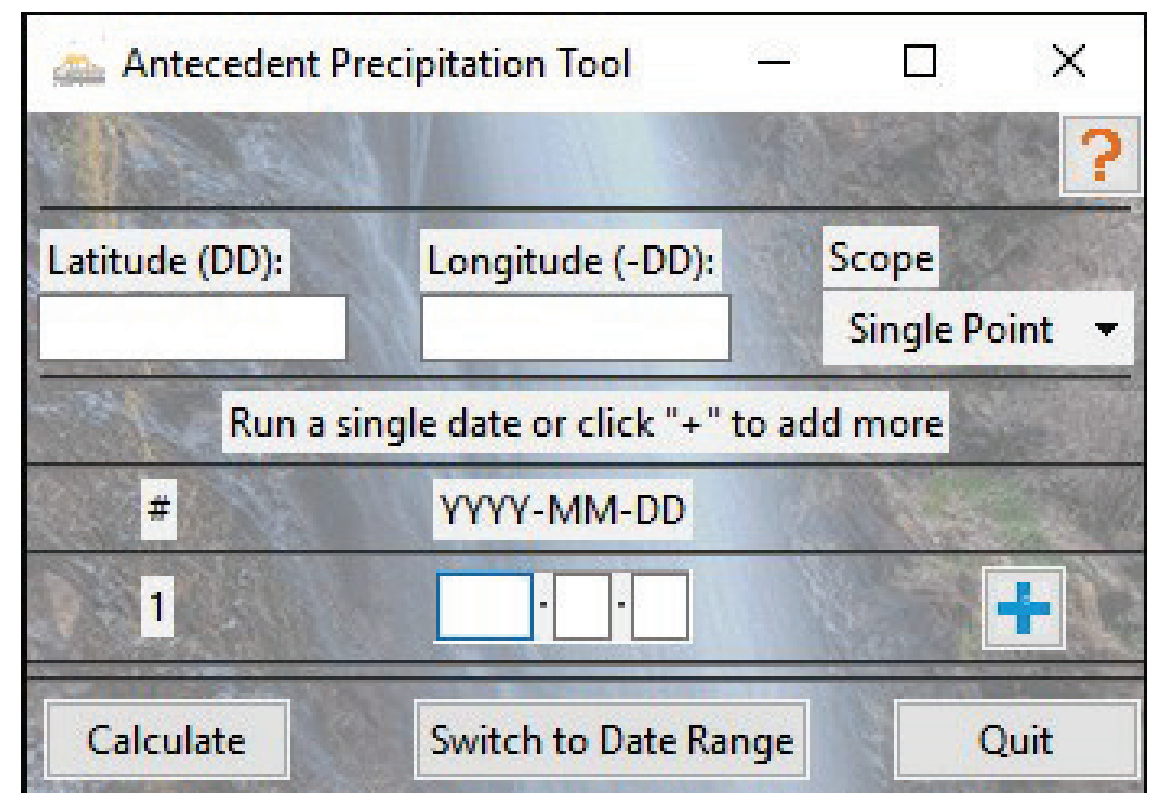

Figure 1. The APT Version $1.0 \mathrm{GUI}$.

User interactions with the APT primarily take place within the GUI. A series of walkthroughs on how to access APT functionality using the GUI accompany this user and technical guide. Each walkthrough illustrates the specific process undertaken for each permutation of the APT usage. Therefore, this technical and user guide will not cover specific operational steps within the APT.

\section{Output Description}

After completion of each APT run, the APT will provide several outputs. The folder containing these outputs will automatically open on the user's machine following completion of each APT analysis. This folder will be present in the "Outputs" directory within the "Antecedent Precipitation Tool" directory. The "Outputs" directory will organize APT output according to the APT version that conducted the analysis. For example, APT Version 1.0.20 output will be within "Outputs/v1_0_20" directory. 
The contents of the folder will vary depending upon the analysis undertaken. In general, the APT output consists of three output types. The first is a portable document format (PDF) file summarizing the APT results, including the Antecedent Precipitation Score, WebWIMP seasonal determination, and PDSI drought determination at both single-point and watershed scales. Figure 2 depicts an example of the single-point summary output provided by the APT. Detailed walkthroughs of each PDF summary accompany this document. The second component of the APT output will be GHCN station data collected and analyzed by the APT and saved as commaseparated value (CSV) files. The third component will be a summary PDF and CSV files, created if the user runs a watershed analysis or multiple dates.

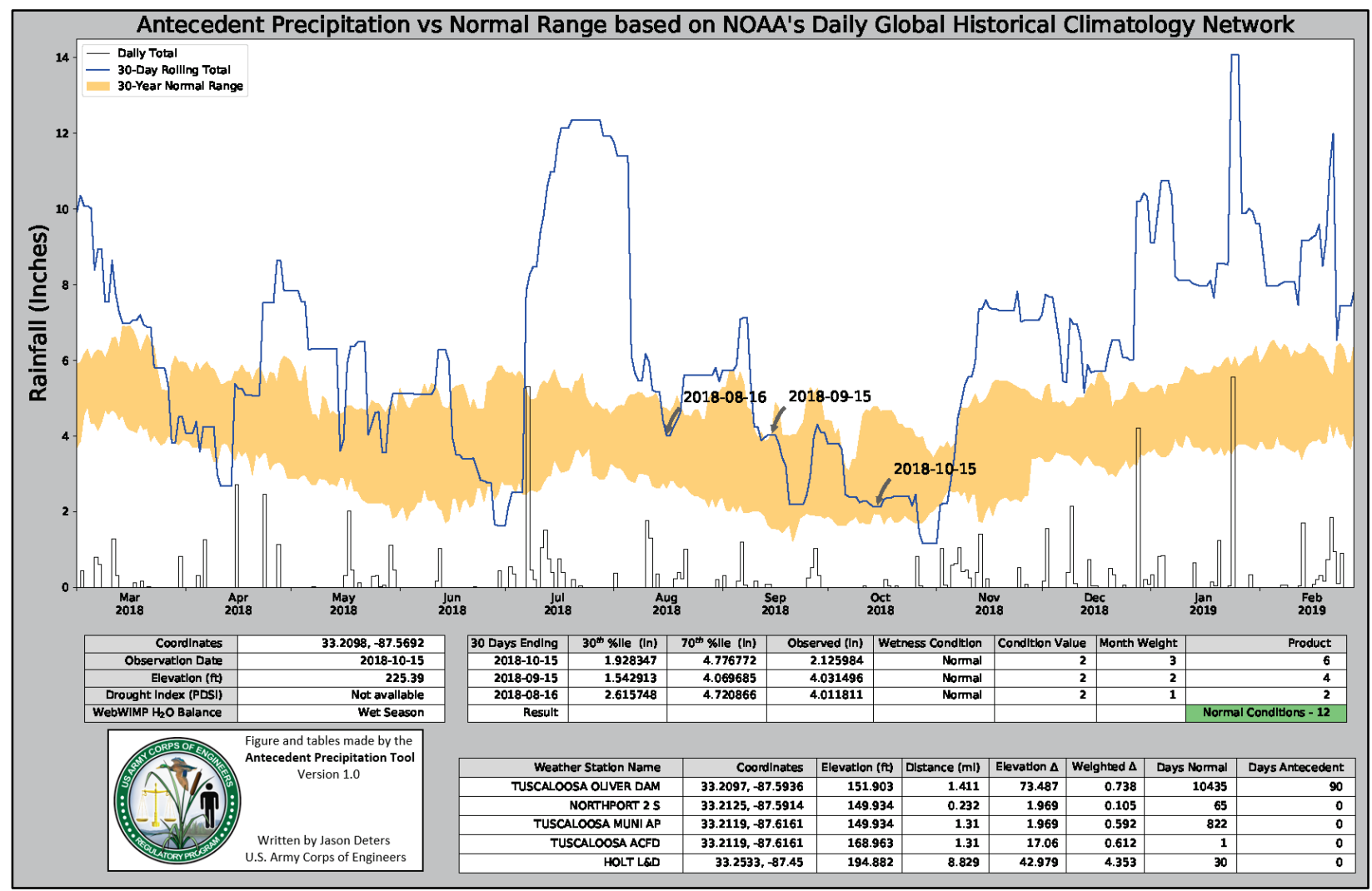

Figure 2. An example of the PDF output provided to the user after an APT single-point analysis.

APT single-point analysis outputs. For a single point analysis, the APT output will be stored within a directory named according to the latitude and longitude of the observation point (e.g., "33.2098, -87.5692"). Within this directory, the APT will provide the user with the two APT outputs. The first output will be a PDF summary that resembles Figure 2.

The second component of APT output, the GHCN weather station data will be in a directory titled "Station Data" and will be stored as CSV files. All data from each of the GHCN stations listed in the weather station table in Figure 2 will be output as CSV data and will be titled " $<$ name of the GHCN station $>$ _ year of observation date $>-<$ month of observation date $>-<$ day of observation date>.csv" (e.g., HOLT L\&D_2011-01-01.csv). Two of the CSV files contain the merged GHCN data that the APT uses to determine the Antecedent Precipitation score for the observation point and Observation Data. The titles of these merged data files will be "merged_stations_<year of observation date>-<month of observation Date>-<day of observation date>.csv" (e.g., 
merged_stations_2011-01-01.csv) and "merged_stations_converted_to_in_<year of observation date $>_{-}<$month of observation date $>-<$day of observation date>.csv" (e.g., merged_stations_converted_to_in_2011-01-01.csv). Table 4 is a data dictionary for each of these CSV files that are output by the APT within the "Station Data" directory.

\begin{tabular}{|c|c|}
\hline Column & Description \\
\hline Column 1 & Date of each precipitation observation expressed in YYYY-MM-DD format. \\
\hline Column 2 & $\begin{array}{l}\text { Depth of each daily precipitation observation. Units of } 10^{*} \mathrm{~mm} \text { for " }<\text { name of the GHCN } \\
\text { staton>_<year of observation date }>-<\text { month of observation date }>-<\text { day of observation } \\
\text { date>.csv" and "merged_stations_<year of observation date }>-<\text { month of observation } \\
\text { date>-<day of observation date>.csv". Units of inches for } \\
\text { "merged_stations_converted_to_in_<year of observation date }>-<\text { month of observation } \\
\text { date>-<day of observation date>.csv". }\end{array}$ \\
\hline
\end{tabular}

Running an APT single-point analysis for multiple observation dates, as a batch process, will yield the same data provided by the single-point analysis for each observation point and observation date. This output will reside in the same directory as a single-point, single observation date analysis. In addition, the APT will provide the user with a summary PDF and CSV file. The PDF will be a compilation of summary plots for each observation date and will be named " $(<$ latitude of the observation point $>$, <longitude of the observation point $>$ ) Batch Result.pdf' (e.g., (33.2098, -87.5692) Batch Result.pdf). The CSV file will summarize each observation date for the observation point and will be named "(<latitude of the observation point $>$, <longitude of the observation point $>$ ) Batch Result.csv" (e.g., (33.2098, -87.5692) Batch Result.csv). Table 5 is a data dictionary of the CSV summary file.

\begin{tabular}{|c|l||}
\hline \multicolumn{1}{|l||}{ Table 5. Data Dictionary for the APT merged_stations_<observation date>.csv file. } \\
\hline \hline Column & \multicolumn{1}{c||}{ Description } \\
\hline Latitude & Latitude of the observation point, in degrees. \\
\hline Longitude & Longitude of the observation point, in degrees. \\
\hline Date & Date of the observation date, expressed as YYYY-MM-DD. \\
\hline PDSI Class & $\begin{array}{l}\text { PDSI drought determination for the observation point and observation date. } \\
\text { Expressed as one of 12 different categories: Not available, Extreme wetness, } \\
\text { Severe wetness, Moderate wetness, Mild wetness, Incipient wetness, Normal, } \\
\text { Incipient drought, Mild drought, Moderate drought, Severe drought, Extreme } \\
\text { drought (Table 3). }\end{array}$ \\
\hline Season & $\begin{array}{l}\text { WebWIMP seasonal determination for the observation point and observation date. } \\
\text { Expressed as one of two different categories: Wet Season, Dry Season (Table 2). }\end{array}$ \\
\hline Antecedent & $\begin{array}{l}\text { Antecedent Precipitation Score determination for the observation point and } \\
\text { observation date. Integer value that will range between 6 and 18. }\end{array}$ \\
\hline $\begin{array}{c}\text { Antecedent } \\
\text { Precipitation }\end{array}$ & $\begin{array}{l}\text { Descriptive summary for the Antecedent Precipitation Score. Expressed as one of } \\
\text { three different categories: Normal Conditions, Wet Conditions, or Dry Conditions } \\
\text { (Table 1). }\end{array}$ \\
\hline
\end{tabular}


APT watershed analysis outputs. For watershed analyses, the APT creates a separate subdirectory within the "Outputs" directory named " Watershed". Within this directory, the watershed scale will separate different watershed runs. HUC 12 outputs will fall within the "HUC12" directory. HUC 10 outputs will fall within the "HUC10" directory. HUC 8 outputs will fall within the "HUC8" directory. Custom polygon outputs will fall under the "Custom Polygon" directory. Below the watershed scale directory, the unique identifier for the HUC or the custom polygon will define the sub-directory name. For example, if a HUC12 analysis is undertaken at observation point with a latitude of 33.2098 and longitude of -87.5692 , the directory containing this watershed analysis will be "Outputs|v1_0_19| Watershed $|H U C 12| 031601120505$ ".

Within each watershed analysis directory, two general types of files will be present. The first is a PDF summary that contains a summary of the watershed analysis on the first page (Figure 3) and an APT single-point summary for each sampling point used in the watershed analysis on subsequent pages (Figure 2). The APT watershed summary will be named " $<$ year of observation date $>_{-}<$month of observation date $>_{-}<$day of observation date $>-<$watershed name $>-$Batch Result.pdf' (e.g., 2011-01-01 - 031601120505 - Batch Result.pdf). The second output of the APT watershed analysis is a CSV file containing a summary of each sampling point used in the watershed analysis. Table 6 is the data dictionary for the watershed analysis summary CSV file. The CSV file will be named "<year of observation date $>-<$ month of observation date $>-<$ day of observation date > - <watershed name > - Sampling Results.csv" (e.g., 2011-01-01 - 031601120505 - Sampling Results.csv). The APT watershed analysis will also generate single-point analysis outputs for each sampling point used in the watershed analysis. The APT stores these single-point results within the same directory as all other APT single-point analysis outputs.

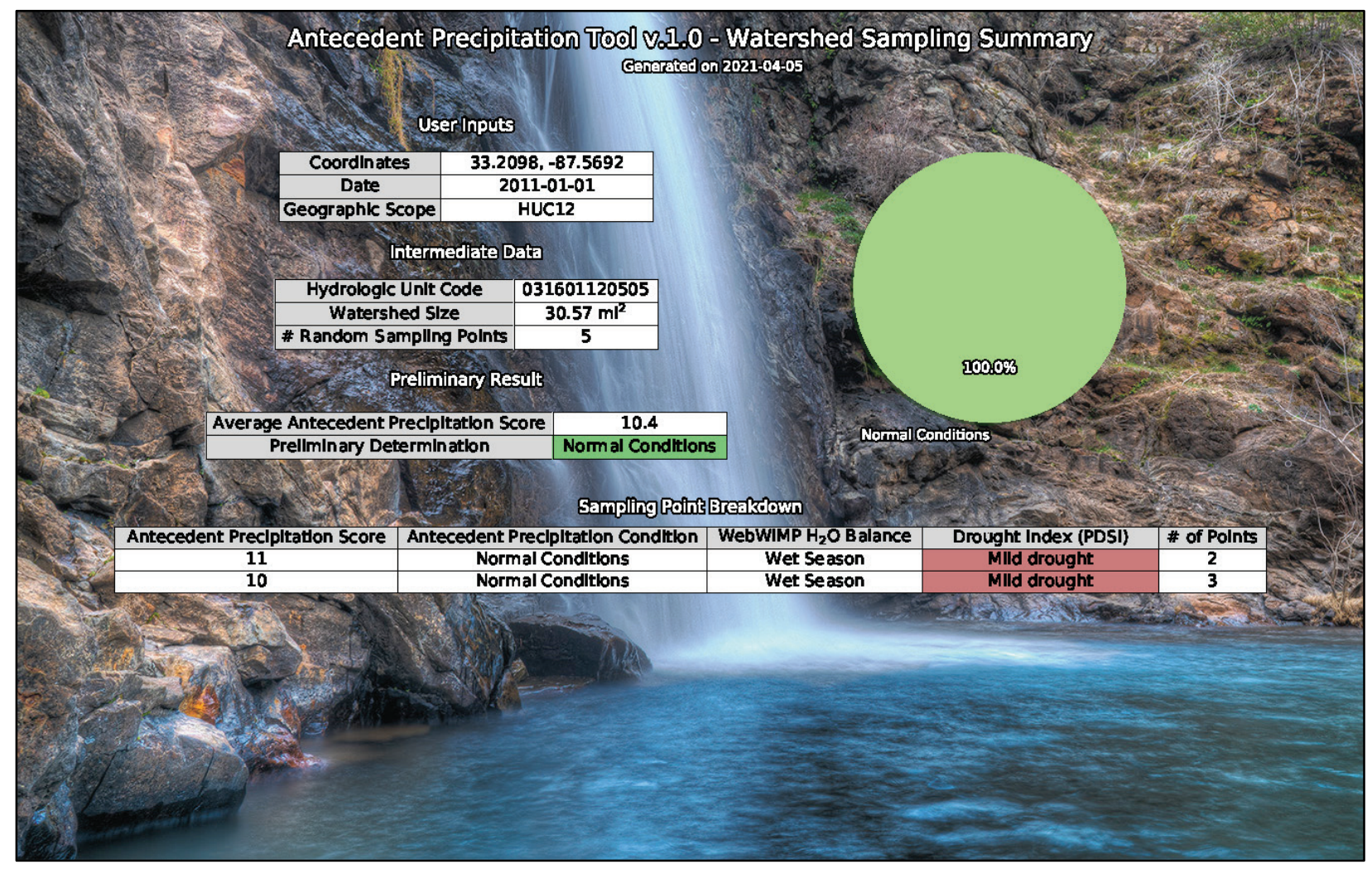

Figure 3. Example of an APT watershed summary. 


\begin{tabular}{|c|c|}
\hline Column & Description \\
\hline Latitude & Latitude of the sampling point, in degrees. \\
\hline Longitude & Longitude of the sampling point, in degrees. \\
\hline Date & Date of the observation date, expressed as YYYY-MM-DD. \\
\hline PDSI Value & $\begin{array}{l}\text { PDSI value for the sampling point on the observation date. Decimal value that } \\
\text { typically ranges from }-6 \text { to } 6 \text {. Negative values indicate dry conditions and positive } \\
\text { values indicate wet conditions. }\end{array}$ \\
\hline PDSI Class & $\begin{array}{l}\text { PDSI drought determination for the sampling point and observation date. } \\
\text { Expressed as one of } 12 \text { different categories: Not available, Extreme wetness, } \\
\text { Severe wetness, Moderate wetness, Mild wetness, Incipient wetness, Normal, } \\
\text { Incipient drought, Mild drought, Moderate drought, Severe drought, Extreme } \\
\text { drought (Table 3). }\end{array}$ \\
\hline Season & $\begin{array}{l}\text { WebWIMP seasonal determination for the sampling point and observation date. } \\
\text { Expressed as one of two different categories: Wet Season, Dry Season (Table 2). }\end{array}$ \\
\hline $\begin{array}{c}\text { Antecedent } \\
\text { Precipitation Score }\end{array}$ & $\begin{array}{l}\text { Antecedent Precipitation Score determination for the sampling point and } \\
\text { observation date. Integer value that will range between } 6 \text { and } 18 .\end{array}$ \\
\hline $\begin{array}{l}\text { Antecedent } \\
\text { Precipitation } \\
\text { Condition }\end{array}$ & $\begin{array}{l}\text { Descriptive summary for the Antecedent Precipitation Score at the sampling point } \\
\text { and observation date. Expressed as one of three different categories: Normal } \\
\text { Conditions, Wet Conditions, or Dry Conditions (Table 1). }\end{array}$ \\
\hline
\end{tabular}

\section{Diagnosing and Addressing APT Errors}

The following sections highlight common issues encountered while using the APT and ways to address these issues. At any time, the user may contact USACE directly for questions regarding the APT at APT-Report-Issue@usace.army.mil.

NOAA GHCN errors. The APT calculates the Antecedent Precipitation Score using the NOAA GHCN network of weather stations. GHCN data reside on the NOAA servers, and the APT accesses the data on demand. If the GHCN data service is down, the APT-DOS window will inform the user that the data service appears to be offline. Further, the user may note erroneous data such as the Antecedent Precipitation Score calculations in Figure 4. If the user experiences GHCN downtime or finds erroneous precipitation values, the user should communicate these errors to the NOAA GHCN-Daily team that is currently composed of Bryant Korzeniewski (bryant.korzeniewski@noaa.gov) and Matthew Menne (matthew.menne@,noaa.gov). 


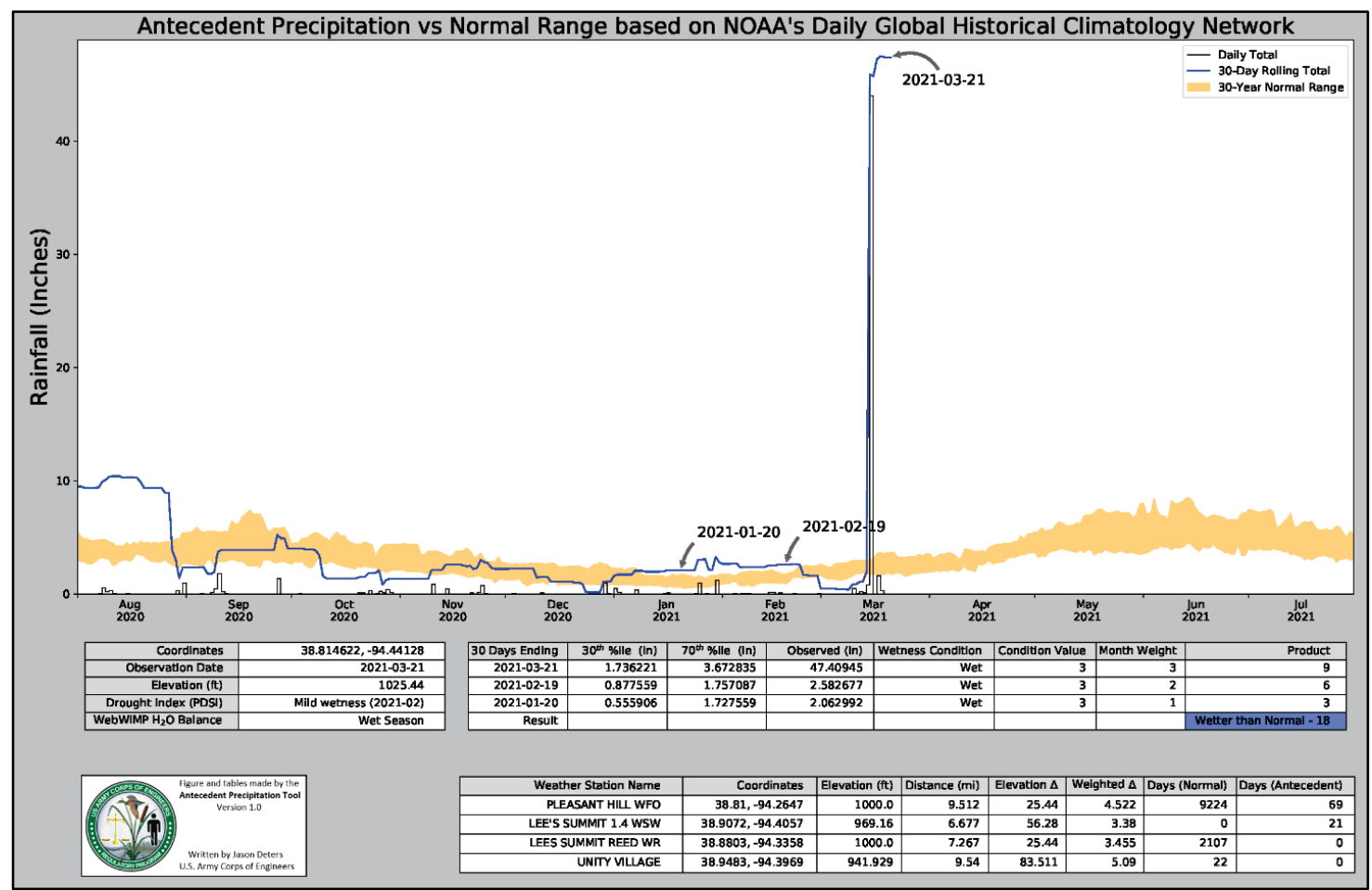

Figure 4. Erroneously high daily precipitation value reported on the GHCN servers that caused a significant skew in the APT Antecedent Precipitation Score results.

USGS EPQS errors. The APT also queries the USGS EPQS web services on demand to acquire an elevation estimate at each GHCN station. The user may experience intermittent downtime with the USGS EPSG services as well. If the APT is unable to use USGS EPSG services, the APT will report this in the APT-DOS window. If the user encounters downtime in the USGS EPSG services, the user is encouraged to report the issue directly to the USGS National Map team at tnmhelp@usgs.gov.

PDSI and WebWIMP errors. Occasionally, the APT will determine that the PDSI is "Not available" and will provide a PDSI value of -99.99 in summary CSV files. This occurs when the PDSI data for a particular observation point are unavailable within the NOAA nClimDiv dataset or if the observation point does not fall within one of the NOAA climate divisions. Also, the APT will omit WebWIMP seasonal determinations in the summary PDF and CSV files if an observation point does not fall within the WebWIMP domain. Although the WebWIMP domain covers all the land surface of Earth, observation points near the coastal areas may erroneously be determined to be within the local waterbody and not within the WebWIMP domain.

Primary station determination errors. After each APT run, the user should monitor the MSDOS window. In instances where the APT operates in remote environments, the APT may be unable to designate a primary station because of faulty data or a lack of stations that meet the minimum station record specifications. In such instances, the MS-DOS window will prompt the user to restart the program and will print the specific error encountered. Figure 5 illustrates one instance where data issues appear to have made the APT unable to select a primary station. Under such circumstances, the user may be unable to operate the APT for the observation point and 
observation date for the short-term. The user should make sure to close and reopen the APT under such circumstances before continuing operation.

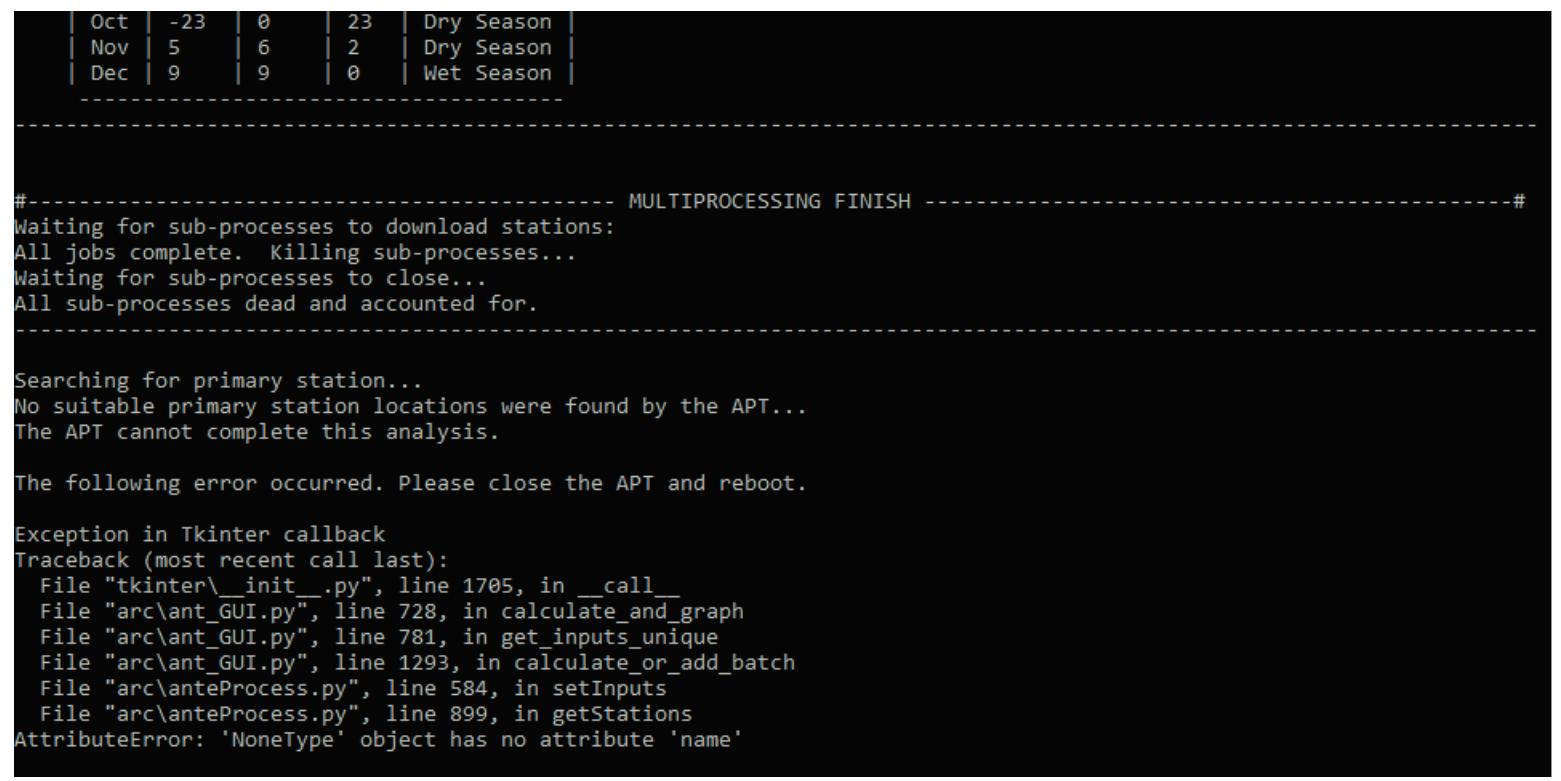

Figure 5. An example of an error report in the APT MS-DOS window encountered when selecting the primary station. These issues typically occur in remote locations. Remember to restart the APT after encountering such issues.

APT LIMITATIONS: Other accurate and reliable measurements of precipitation normalcy, as well as other sources of climatic data, relevant to the aquatic resource under evaluation may be available. For example, the agencies recognize that precipitation is only one part of the water budget and that the impact of antecedent precipitation on streamflows or surface water connections may vary with place and time. The impact of precipitation on streamflow and surface water connectivity can vary depending on a combination of additional factors such as precipitation type, precipitation distribution, temperature, anthropogenic influences, and the physical composition of a watershed (Sprecher and Warne 2000; Slater and Villarini 2017). Therefore, the agencies may consider data on snowpack, specifically snow water equivalent, for certain regions and certain times of the year (e.g., using the NOAA National Operational Hydrologic Remote Sensing Center [NOAA 2020]). The agencies may also consider other data sources such as certain drought indices (e.g., PDSI [Palmer 1965], US Drought Monitor [National Drought Mitigation Center 2021], and others) or operational hydrologic models (e.g., the National Water Model [NOAA 2021b]).

Other data sources such as drought monitors and hydrologic models incorporate multiple hydrologic inputs and may better capture the impact of precipitation and other meteorological variables on terrestrial hydrologic systems (Haslinger et al. 2014; Tijdeman et al. 2018). Investigations are ongoing that will provide enhanced guidance on how USACE project managers should utilize the APT within the context of other existing tools in determinations of normal hydroclimatic conditions.

ACKNOWLEDGEMENTS: The USACE, Wetlands Regulatory Assistance Program (WRAP), provided funding to support this research. Damaris Christensen, Rachel Harrington, Whitney 
Beck, and Julia Kelso of EPA and Kent Sparrow of the US Army Engineer Research and Development Center (ERDC) provided technical review of this document.

POINTS OF CONTACT: For additional information, contact Dr. Joseph L. Gutenson, ERDC, Vicksburg, MS (601-287-1436; Joseph.L.Gutenson@erdc.dren.mil) or the Program Manager of WRAP, Mr. Kyle B. Gordon (601-634-3717; Kyle.B.Gordon@usace.army.mil). This technical note should be cited as follows:

Gutenson, J. L., and J. C. Deters. 2022. Antecedent Precipitation Tool (APT)

Version 1.0: Technical and User Guide. ERDC/TN WRAP-22-1. Vicksburg, MS: US Army Engineer Research and Development Center. http://dx.doi.org/10.21079/11681/43160

\section{REFERENCES}

AMS (American Meteorological Society). 2012. Potential Evapotranspiration. https://glossary.ametsoc.org/wiki/Potential evapotranspiration

Dai, A. 2011. "Characteristics and Trends in Various Forms of the Palmer Drought Severity Index during 19002008." Journal of Geophysical Research Atmospheres 116(12). https://doi.org/10.1029/2010JD015541

Dai, A. 2012. Palmer Drought Severity Index (PDSI). https://climatedataguide.ucar.edu/climate-data/palmerdrought-severity-index-pdsi

Dai, A., K. E. Trenberth, and T. Qian. 2004. "A Global Dataset of Palmer Drought Severity Index for 1870 - 2002 : Relationship with Soil Moisture and Effects of Surface Warming." Journal of Hydrometeorology 5(6): 11171130. https://doi.org/https://doi.org/10.1175/JHM-386.1

EPA (US Environmental Protection Agency). 2021. WATERS (Watershed Assessment, Tracking \& Environmental Results System). https://www.epa.gov/waterdata/waters-watershed-assessment-tracking-environmentalresults-system

ESRI (Environmental Systems Research Institute). 2022. Watershed (Ready to Use). https://pro.arcgis.com/en/pro-app/latest/tool-reference/ready-to-use/watershed.htm

Gesch, D., G. Evans, J. Mauck, J. Hutchinson, and W. J. Carswell Jr. 2010. The National Map - Elevation. https://pubs.usgs.gov/fs/2009/3053/

Gesch, D., M. Oimoen, S. Greenlee, C. Nelson, M. Steuck, and D. Tyler. 2002. "The National Elevation Dataset: Photogrammetric Engineering and Remote Sensing." Journal of the American Society for Photogrammetry and Remote Sensing 68: 5-11.

Haslinger, K., D. Koffler, W. Schoner, and G. Laaha. 2014. "Exploring the Link between Meteorological Drought and Streamflow: Effects of Climate-Catchment Interaction." Water Resources Research 50(3): 2468-2487. https://doi.org/10.1002/2013WR015051

Lang, D., J. Zheng, J. Shi, F. Liao, X. Ma, W. Wang, X. Chen, and M. Zhang. 2017. “A Comparative Study of Potential Evapotranspiration Estimation by Eight Methods with FAO Penman-Monteith Method in Southwestern China." Water 9(10): 734. https://doi.org/10.3390/w9100734 
Menne, M. J., I. Durre, R. S. Vose, B. E. Gleason, and T. G. Houston. 2012. "An Overview of the Global Historical Climatology Network-Daily Database.” Journal of Atmospheric and Oceanic Technology 29(7): 897-910. https://doi.org/10.1175/JTECH-D-11-00103.1

National Drought Mitigation Center. 2021. US Drought Monitor. https://droughtmonitor.unl.edu/CurrentMap.aspx

NOAA (National Oceanic and Atmospheric Administration). 2005. Drought Indices: Explanation. https://www.cpc.ncep.noaa.gov/products/analysis_monitoring/cdus/palmer_drought/wpdanote.shtml

NOAA. 2014. nClimDiv: Statewide-Regional-National Drought. https://www1.ncdc.noaa.gov/pub/data/cirs/climdiv/drought-readme.txt

NOAA. 2020. National Operational Hydrologic Remote Sensing Center: Interactive Snow Information. https://www.nohrsc.noaa.gov/interactive/html/map.html

NOAA. 2021a. Global Historical Climate Network Daily-Description. https://www.ncdc.noaa.gov/ghcn-dailydescription

NOAA. 2021b. National Water Model. https://water.noaa.gov/about/nwm

NRCS (Natural Resources Conservation Service). 1997. "Hydrology Tools for Wetland Determination." Part 650 Engineering Field Handbook (August). US Department of Agriculture. https://directives.sc.egov.usda.gov/OpenNonWebContent.aspx? content $=17556 . w b a$

Palmer, W. C. 1965. “Meteorological Drought.” US Weather Bureau, Res. Pap. No. 45. https://www.ncdc.noaa.gov/temp-and-precip/drought/docs/palmer.pdf

Seaber, P. R., F. P. Kapinos, and G. L. Knapp. 1987. "Hydrologic Unit Maps.” US Geological Survey Water-Supply Paper 2294. https://doi.org/10.3133/wsp2294

Slater, L. J., and G. Villarini. 2017. "Evaluating the Drivers of Seasonal Streamflow in the US Midwest." Water (Switzerland) 9(9): 1-22. https://doi.org/10.3390/w9090695

Sprecher, S. W., and A. G. Warne. 2000. Accessing and Using Meteorological Data to Evaluate Wetland Hydrology. https://apps.dtic.mil/dtic/tr/fulltext/u2/a378910.pdf

Thornthwaite, C. W. 1948. "An Approach toward a Rational Classification of Climate." Geographical Review 38(1): 55-94. https://doi.org/10.2307/210739

Tijdeman, E., L. J. Barker, M. D. Svoboda, and K. Stahl. 2018. "Natural and Human Influences on the Link Between Meteorological and Hydrological Drought Indices for a Large Set of Catchments in the Contiguous United States.” Water Resources Research 54(9): 6005-6023. https://doi.org/10.1029/2017WR022412

University of Delaware. 2009. WebWIMP: The Web-Based, Water-Budget, Interactive, Modeling Program. http://climate.geog.udel.edu/ wimp/

USACE (US Army Corps of Engineers). 2008. Regional Supplement to the Corps of Engineers Wetland Delineation Manual: Great Arid West Region (Version 2.0). https://usace.contentdm.oclc.org/utils/getfile/collection/p266001coll1/id/7627

USGS (US Geological Survey). 2017. The National Map - Elevation Point Query Service. https://nationalmap.gov/epqs/ 
USGS and NRCS (Natural Resources Conservation Service). 2013. "Federal Standards and Procedures for the National Watershed Boundary Dataset (WBD).” In Section A, Federal Standards, Book 11, Collection and Delineation of Spatial Data, Fourth, 63. Reston, VA: US Geological Survey. http://pubs.usgs.gov/tm/11/a3/

van der Schrier, G., P. D. Jones, and K. R. Briffa. 2011. "The Sensitivity of the PDSI to the Thornthwaite and Penman-Monteith Parameterizations for Potential Evapotranspiration.” Journal of Geophysical Research Atmospheres 116(3): 1-16. https://doi.org/10.1029/2010JD015001

Vepraskas, M. J., Berkowitz, J. F., and C. Arellano. 2019. "Determining Normal Precipitation Ranges for Hydric Soil Assessments." Soil Science Society of America Journal 83(2): 503-510.

Vose, R. S., S. Applequist, M. Squires, I. Durre, C. J. Menne, C. N. Williams, C. Fenimore, K. Gleason, and D. Arndt. 2014. "Improved Historical Temperature and Precipitation Time Series for US Climate Divisions." Journal of Applied Meteorology and Climatology 53(5): 1232-1251. https://doi.org/10.1175/JAMC-D-13$\underline{0248.1}$

Willmott, C. J., J. R. Mather, and C. M. Rowe. 1981a. Average Monthly and Annual Surface Air Temperature and Precipitation Data for the World: Part 1: The Eastern Hemisphere. CW Thornthwaite Associates Laboratory of Climatology.

Willmott, C. J., J. R. Mather, and C. M. Rowe. 1981b. Average Monthly and Annual Surface Air Temperature and Precipitation Data for the World: Part 2: The Western Hemisphere. CW Thornthwaite Associates Laboratory of Climatology.

Willmott, C. J., C. M. Rowe, and Y. Mintz. 1985. “Climatology of the Terrestrial Seasonal Water Cycle.” Journal of Climatology 5: 589-606. https://doi.org/https://doi.org/10.1002/joc.3370050602

NOTE: The contents of this technical note are not to be used for advertising, publication, or promotional purposes. Citation of trade names does not constitute an official endorsement or approval of the use of such products. 